\title{
Physician Training Related to Environmental Hazards Near Ash Superfund Sites
}

\author{
Alan Becker ${ }^{1}$, Rima Tawk ${ }^{1 *}$, Gebre Kiros ${ }^{1}$, Sandra Suther ${ }^{1}$, Aaron Hilliard ${ }^{1}$, Richard Gragg ${ }^{2}$, Fran Close ${ }^{1}$, \\ Cynthia M. Harris ${ }^{1}$
}

\footnotetext{
${ }^{1}$ Florida A\&M University, College of Pharmacy, Pharmaceutical Sciences and Institute of Public Health, Tallahassee, FL, USA

${ }^{2}$ Florida A\&M University, School of the Environment, Tallahassee, FL, USA

*Corresponding Author: rima.tawk@famu.edu
}

Citation: Becker, A., Tawk, R., Kiros, G., Suther, S., Hilliard, A., Gragg, R., Close, F. and Harris, C. M. (2021). Physician Training Related to Environmental Hazards Near Ash Superfund Sites. European Journal of Environment and Public Health, 5(2), em0086. https://doi.org/10.21601/ejeph/11096

ARTICLE INFO

Received: 22 Mar. 2021

Accepted: 2 Jun. 2021

\begin{abstract}
Physicians do not receive formal environmental health training in medical schools. The objectives of this study were to provide health care providers with basic environmental medicine training to better advise, treat or refer patients in the community and to observe any differences in the environmental medicine learning gains pre/posttest assessment. To rectify the problem of the lack of physicians' training related to environmental hazards, we conducted an environmental health workshop which targeted physicians living near Health Zone 1, Superfund ash sites. Fifty health care providers from both St. Vincent Family Medicine and Department of Health, Duval County Health Department (DOH-Duval) participated in a pre-test survey before the training and a post-test survey following the training. We used a non-parametric Wilcoxon Signed-Rank test to compare pre- and postknowledge of training participants. At the $10 \%$ level of significance, the number of incorrect answers significantly declined in the post-training survey compared to the pre-training survey for all participants from both facilities combined ( $\mathrm{p}=0.083)$. Site-specific analysis show, while a significant difference was found for participants from the St. Vincent's site ( $p=0.084)$, the difference for participants from the DOH-Duval site was not significant $(p=$ 0.102 ), although the number of incorrect answers declined. The training resulted in learning gains for the 50 participants and the evaluations were very positive with $100 \%$ of physicians recommending this training to other health care providers. Additionally, training participants gave a high mark for the environmental medicine pocket guide. In 2019, the ash sites are 90\% remediated and cleanup is expected to be completed in 2022 . There is still a need for additional training for physicians due to other active sites (i.e., Kerr-McGee) in the community. This study highlights the importance of providing environmental hazards training to physicians and the approach by which it could be delivered effectively.
\end{abstract}

Keywords: physician environmental medicine training, exposure to environmental hazards, curriculum development, community Research, superfund sites, Jacksonville, Florida

\section{INTRODUCTION}

While working with the community members living near the Jacksonville Superfund Ash Site, we became aware that residents' questions and concerns related to environmental and occupational hazards were not being addressed by their primary caregivers. The gap in physicians' environmental health training initiated the development of this training workshop to include resources for continuing education and some free resources. We were unable to find in the literature a similar environmental medicine workshop for physicians which measured the effectiveness through learning gains and evaluation of environmental hazards training.
The environmental medicine training workshop was developed under the grant from United States, Department of Health and Human Services, Agency for Toxic Substances Disease Registry (U.S., D.H.H.S., A.T.S.D.R.) titled Racial and Ethnic Environmental Approaches to Community Health (REEACH) Project, in partnership with Florida A\&M University (FAMU) and the DOH-Duval. The training goals were to enhance knowledge of environmental contaminants, to evaluate patients with an exposure history form, and to recognize environmental-related diseases.

\section{Demographics of Health Zone 1}

It has been well documented that the urban core in Health Zone 1 of Jacksonville has experienced disparities in the African American Community related to environmental justice 
issues such as poverty, dilapidated housing, stressors, mistrust related to the cleanup of the Superfund ash sites (Becker et al. 2019). The population is currently 113,249 for Health Zone 1 (United Zip Codes, 2021). Health zone 1 includes zip codes 32202, 32204, 32206, 32208, 32209 and 32254 and experienced disparities related to environmental justice concerns with 68\% of Health Zone 1 being African American (United Zip Codes, 2021). Seventy three percent of the properties are built pre1978 (United States Census, Duval County Health Department, 2000), which increased risk of exposure to lead in paint. Children make up a sizable portion of the population with 12.8 $\%$ children $<$ than 9 years old and $7 \%<$ than 5 years old (United States Census for Duval County, 2000). In addition, $43 \%$ of the children live in poverty (Bureau of Labor Statistics, 2009; United States Census for Duval County, 2000).

\section{Jacksonville Ash Site and Contaminants}

The Jacksonville Ash Superfund Sites include the Forest Street Incinerator, with 370-acres including mixed residential/commercial McCoy Creek north, single-family homes south, and commercial and industrial business west. The contaminants for Forest Street Incinerator are contaminated with lead, arsenic, polychlorinated dibenzofurans (PCBs), chlorinated dibenzo-dioxin (dioxins), polycyclic aromatic hydrocarbons (PAHs). The 5th \& Cleveland Incinerator is contaminated with arsenic, lead, polycyclic aromatic hydrocarbons (PAHs), polychlorinated dibenzofurans (PCBs) and chlorinated dibenzo-dioxin (dioxins) with 520-acres inclusive of single-family homes, multi-family apartments and four schools, and Emmet Reed Community Center, Emmet Reed Park. Lonnie C. Miller, Sr. Park is contaminated with copper lead, arsenic, chlorinated dibenzo-dioxin (dioxins), polycyclic aromatic hydrocarbons PAHs, polychlorinated dibenzofurans PCBs with 250-acres inclusive of single-family homes to north, south, and east, commercial businesses to the west, and the Ribault River are located east of the park (United States Environmental Protection Agency (U.S., EPA), Jacksonville Ash Site, 2019). Brown's Dump is contaminated with arsenic, lead, copper, polycyclic aromatic hydrocarbons (PCBs), chlorinated dibenzo-dioxin (dioxins).

\section{Physician's Knowledge of Environmental Health}

In a survey of medical academic deans, $73 \%$ indicated that physicians will acquire environmental health knowledge through training or continuing education after medical school (Graber et al., 1995). A perinatal survey found that $57.6 \%$ needed additional training in environmental health (Cecile et al., 2016). A Georgia pediatric study concluded that $53.5 \%$ reported patients seriously affected by environmental exposures with just 20 percent having received training in environmental health (Kilpatrick et al., 2002). A survey in Texas reported $86 \%$ of family physicians had no environmental health training and almost 92\% wanted to learn more about environmental health hazards (Hamilton et al., 2005). Environmental health problems often have symptoms of common medical conditions (e.g., headache, stomach problems, asthma, rashes, lack of concentration, spontaneous abortions) (Wigle, 2000). There have also been delays in asthma diagnosis averaging 4.9 years (Poonai et al., 2005) and only $14 \%$ of patients with adult-onset asthma had their occupation recorded (Walters et al., 2012).

Physicians have a low self-knowledge related to questions from patients related to ground water contamination, polychlorinated biphenyls, lead, mercury, radon, cadmium, and pesticides (Sanborn and Scott, 1998). In another survey, the most frequent patient questions report in previous year by physicians were sunlight (88\%), food additives (71\%), radiation (67\%), lead (52\%), electromagnetic fields (40\%), home pesticides (38\%), groundwater contamination (35\%) and occupational hazards (34\%) (Seaborn and Scott, 1998). In addition, pediatricians reported high confidence with lead exposure but a low confidence with pesticide, mercury, and mold (Trasande et al., 2006).

Basic skills for collecting exposure history and risks associated with environmental disease are important (Pope and Rall, 1995). In a survey conducted in Canada, 92\% of respondents believed that taking an environmental survey history was important, only $18.1 \%$ had specific training and $48.4 \%$ felt that taking an exposure history took too much time (Sanborn et al., 2019). In addition, $77 \%$ of respondents suspected that some cases had an environmental origin (Zachek et al., 2015) but were inconsistent in taking a history. It is critical to organize the exposure history by the possible source or setting by using the areas of possible exposures such as community, home, hobbies, occupation, personal habits, diet and drugs (Marshall et al., 2002). The objectives of this study are twofold, first, to provide health care providers with basic environmental medicine training to better advise, treat or refer patients in the community; and second, to observe any differences in the environmental medicine learning gain pre/post- test assessment.

\section{METHODS}

The environmental medicine training program for medical professionals was organized in four modules that included information related to: 1) knowledge of ash sites U.S., EPA, Cleanup activities, 2021). 2) basics of toxicology and routes of exposure (U.S. D.H.H.S., A.T.S.D.R, Basic Toxicology, 2015; U.S. D.H.H.S., A.T.S.D.R, Routes of Exposure, 2015), 3) risk assessment (U.S. D.H.H.S., A.T.S.D.R, Risk Assessment, 2015). and 4) environmental toxicants of concern (U.S. D.H.H.S., A.T.S.D.R, Survey of Toxic Substances 2015).

All priority health care providers serving residents living in neighborhoods near the City ash sites were contacted for recruitment to the environmental medicine Training. Training Sessions were conducted at DOH Duval primary care providers with 22 completing the program. In addition, St. Vincent's Family Medicine Program (28 residents and faculty) completed the 2-hour training. A pre-test and a posttest were conducted to gauge learning gains.

The pre-and post-assessment questionnaire consisted of 14 items including multiple choice and true and false questions. The difference between pre- and post-test measurements for incorrect answers were calculated by item (each question separately). The values for these differences were ranked from largest to smallest. To test the hypothesis that there is no difference in the median number of incorrect 
Table 1. Pre and post questions answered incorrectly with difference and rank for each question

\begin{tabular}{|c|c|c|c|c|}
\hline Question Subject Areas & Pre & Post & Difference & Rank \\
\hline 1. Knowledge of contamination sites & 11 & 0 & +11 & 4 \\
\hline 2. Contamination of concern in ash sites & 33 & 32 & +1 & 9 \\
\hline 3. Define toxicology & 11 & 4 & +7 & 6 \\
\hline 4. Type of Toxicant & 5 & 14 & -9 & 11 \\
\hline 5. Factors of toxicity & 0 & 4 & -4 & 10 \\
\hline 6. Routes of exposure & 4 & 0 & +4 & 7 \\
\hline 7. What is a chronic exposure? & 4 & 0 & +4 & 7 \\
\hline 8. Recognizing risk assessment process & 37 & 20 & +17 & 1 \\
\hline 9. Effective history form/questionnaire & 20 & 4 & +16 & 2 \\
\hline 10. Most concerning toxicants in ash sites & 35 & 28 & +7 & 6 \\
\hline 11. Is inhalation primary route of exposure? & 7 & 5 & +2 & 8 \\
\hline 12. Main exposure route for arsenic & 10 & 1 & +9 & 5 \\
\hline 13. Chelation treatment & 22 & 10 & +12 & 3 \\
\hline 14. PAHs direct biologic measurement & 17 & 5 & +12 & 3 \\
\hline Total Incorrect Answers & 216 & 127 & +88 & \\
\hline
\end{tabular}

answers between the pre- and post-assessment questions, we used the Wilcoxon Signed-Rank test for paired observations. The Signed Rank test is a non-parametric procedure that does not require any distributional assumptions to be statistically robust. It is comparable to the paired-sample t-test when these distributional assumptions can be made. Our analysis was conducted using SAS version 9.4.

\section{RESULTS}

Based on the pre-/post-test, there was a learning gain computed by subtracting post assessment score from the preassessment score for each question or item for the 50 participants. Our findings show the number of incorrect answers declined in the post assessment phase in 12 out of 14 questions (Table 1).

For the questions related to the knowledge of ash sites, questions 1, 2 and 10 included a (+11), (+1) and (+7) decrease in incorrect answers based on the pre-/post-test related to the knowledge of the ash sites, contamination of the ash sites and most concerning toxicants of ash sites respectively (Table 1). In the area of basics of toxicology, question 4 and 5 had an increase in the number of incorrect answers based on the pre/post-test for type of toxicant (-9) and factors of toxicity (-4), and there was a decrease of incorrect answers based on the pre/post-test related to the question 3 define toxicology (+7) (Table 1). The highest decrease in incorrect answers based on the pre-/post-test was observed for questions 8 and 9 for the risk assessment process (+17) followed by effective history form/questionnaire (+16). In the area of environmental toxicant of concern pertaining to question 12, 13 and 14, there was a decrease in incorrect answers based on the pre-/post-test for main exposure route for arsenic (+9), chelation treatment $(+12)$ and PAHs direct biological measurement $(+12)$, and inhalation as a primary route of exposure $(+2)$ (Table 1$)$. No incorrect answers were reported in the post-assessment phase for question 1, 6, 7 on post-test for knowledge of contamination sites, routes of exposure, and the question "what is a chronic exposure?".

Under the null hypothesis, for a two-sided test, the computed Wilcoxon Signed-Rank test is equal to 1.7318, which represents a p-value of 0.083 (Figure 1). In our preliminary study, we find that a p-value of 0.083 is indicative of a significant effect of our training that warrants further study by increasing the number of sites and participants. At the $10 \%$ level of significance $(\alpha=0.10)$, we can conclude that there is a statistically significant difference between the pre-and posttest measurements per item for the 50 participants. Our results demonstrate that the training has improved the knowledge and understanding of the questions among the participants and there were less incorrect answers after the training.

We also analyzed the data separately for each site. For the St Vincent site, we got similar results. The training has improved participant's knowledge significantly. At $\alpha=0.10$, there is a statistically significant difference $(p=0.084)$ between the pre-and post-test results in each study site Distribution of Wilcoxon Signed-Rank test for St Vincent site (Figure 2).

For participants in the DOH-Duval site, although the number of incorrect answers has declined, the difference is not significant $(\mathrm{p}=0.102)$ (Figure 3$)$.

Training evaluations were very positive with $100 \%$ of physicians recommending the environmental medicine training to other health care providers. In addition, the health care providers were very complementary of provided handouts, especially the DOH-Duval developed environmental medicine pocket guide. The DOH-Duval held several Environmental Medicine workshops for local health care providers who highly praised the usefulness of the presented information and its applicability to their practices.

\section{DISCUSSION}

The purpose of the study was to conduct an environmental medicine workshop for health care providers to better answer environmental concerns for their patients. This training was developed to provide training related to contaminants in the ash site. We also wanted to provide information related to organizations which offer free training and continuing education available from the Wisconsin Environmental Health Network and the Pediatric Environmental Health Specialty Units. We found significant learning gains for both sites combined and for St. Vincent site. 


\section{Dis tribution of Wilcoxon Scores for incorrect}

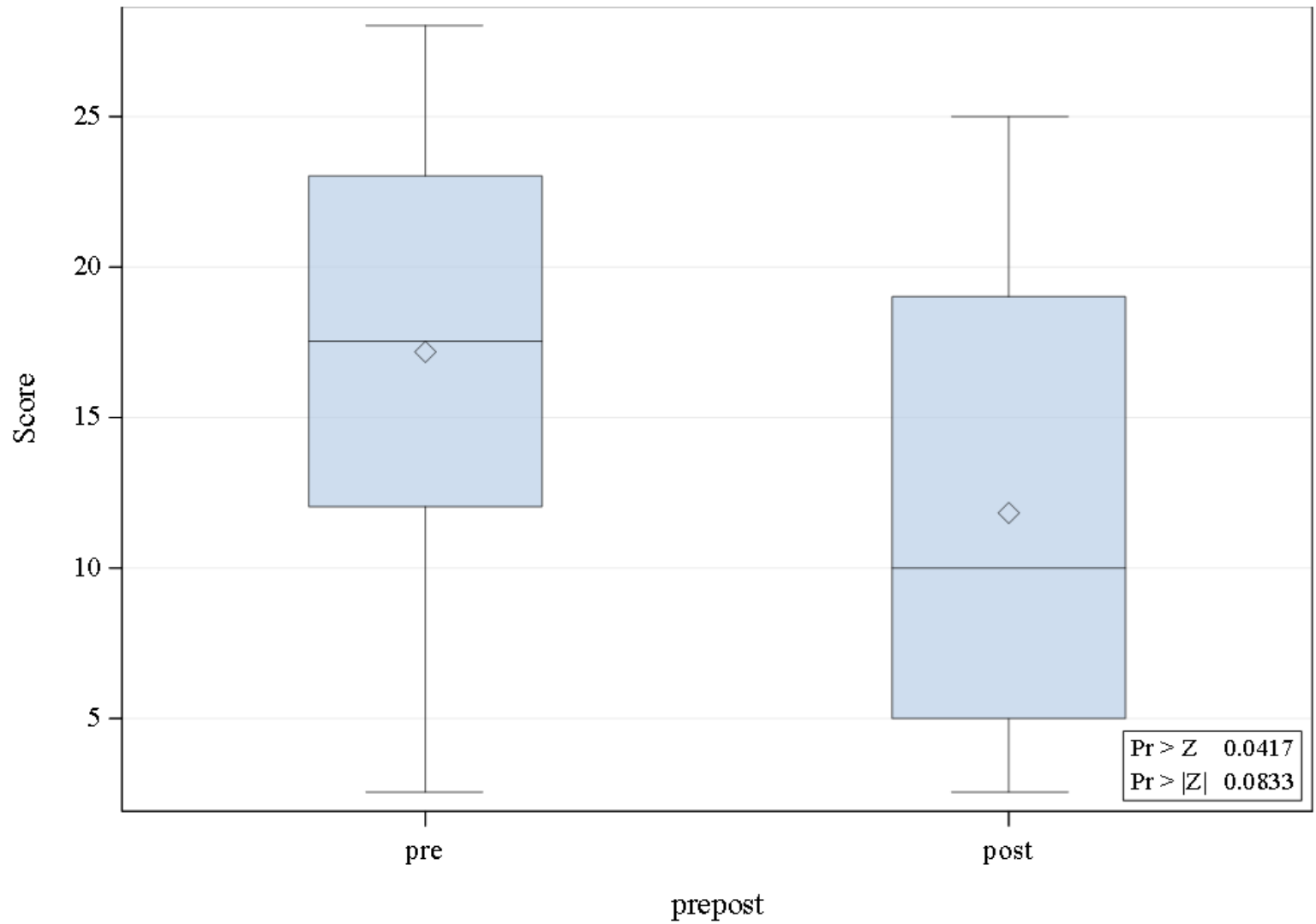

Figure 1. Both St. Vincent and Duval County Health Department distribution of Wilcoxon Scores for incorrect answers (50 participants)

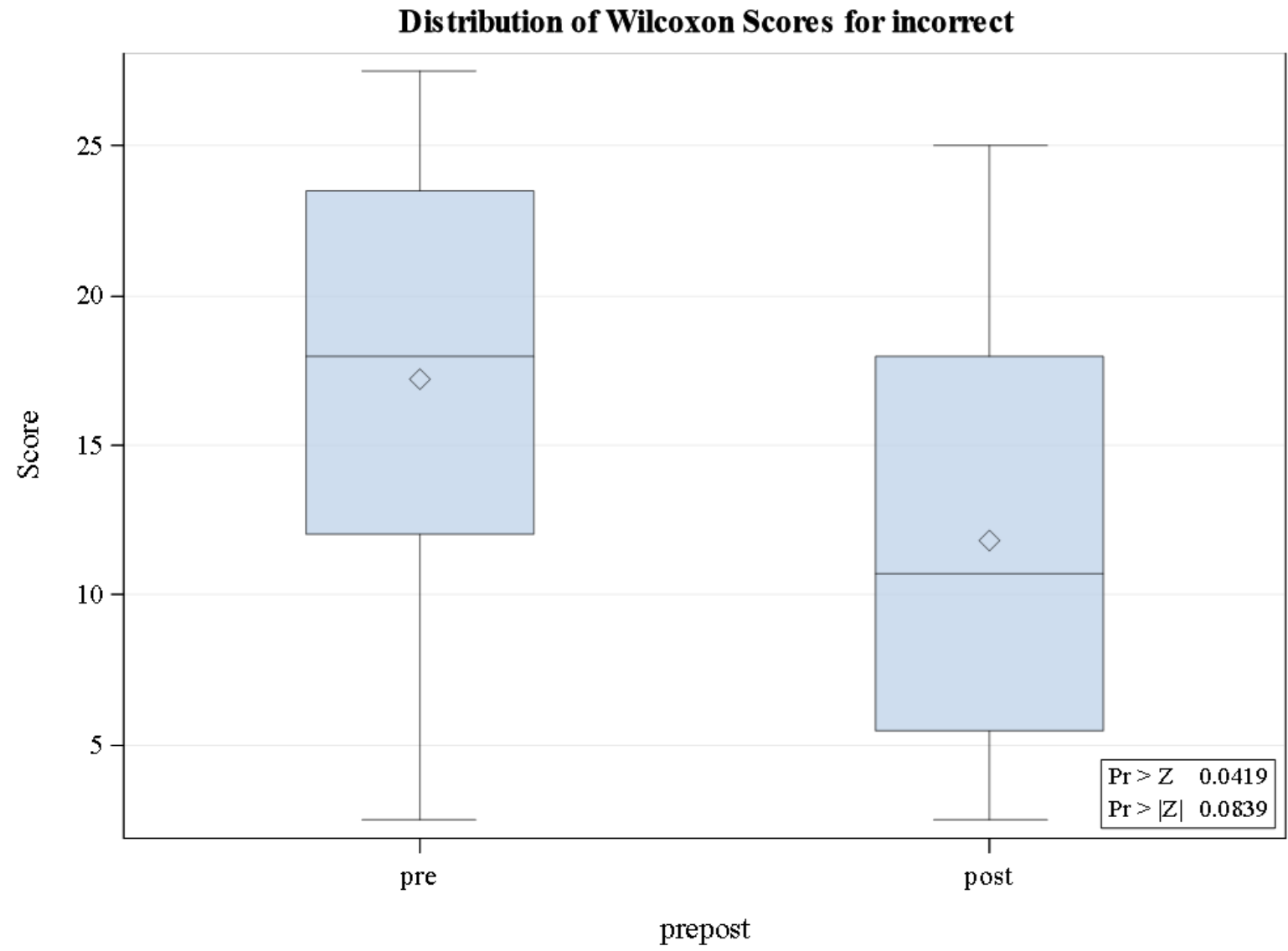

Figure 2. St. Vincent distribution for Wilcoxon Scores for incorrect answers (28 participants) 


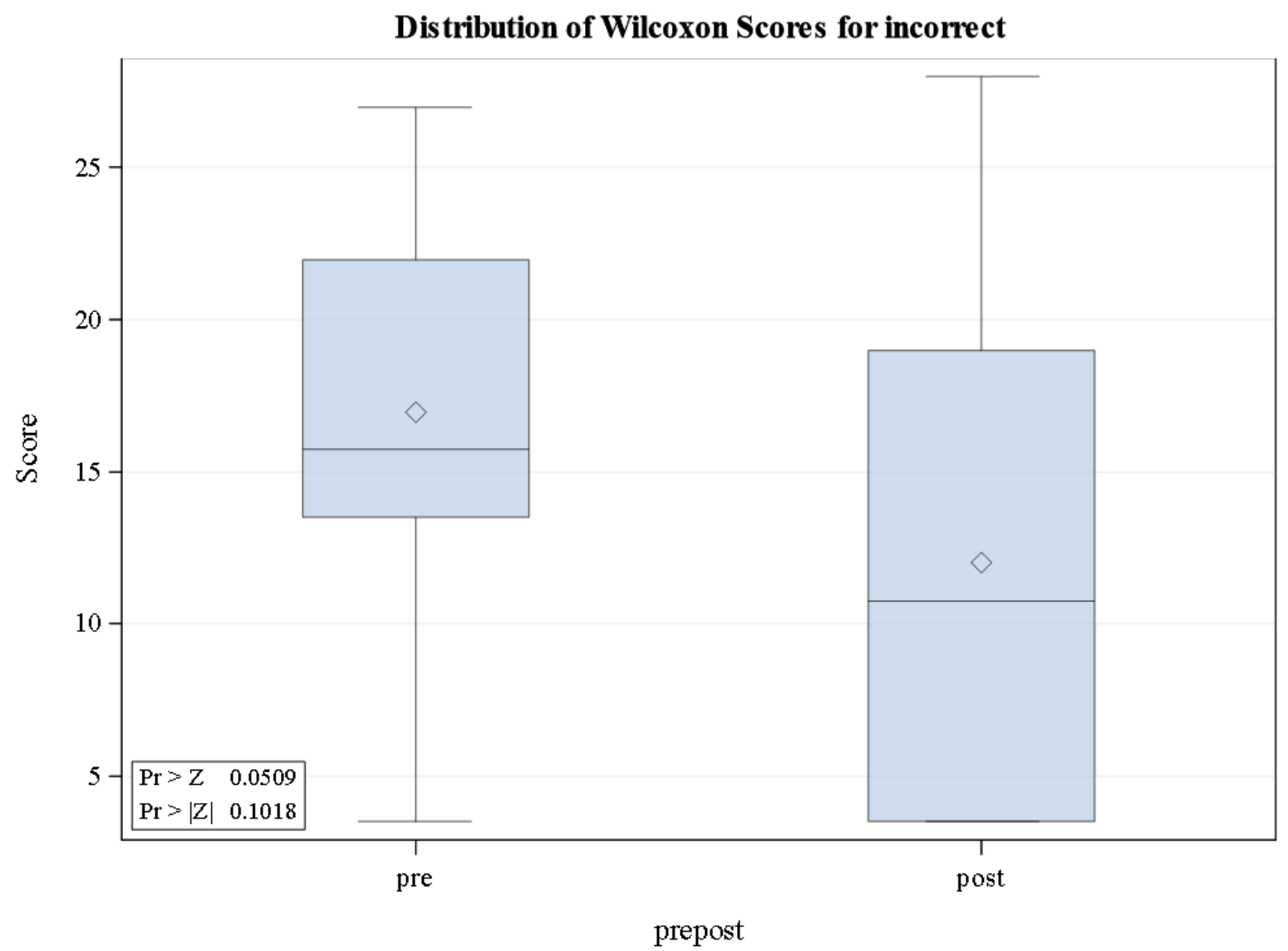

Figure 3. Duval County Health Department distribution of Wilcoxon Scores for incorrect answers (22 participants)

The Environmental Medicine Pocket Guide was developed by the DOH- Duval with funding from the REEACH. It was designed for health care professionals assisting communities impacted by environmental contamination associated with the ash sites. This environmental medicine pocket guide provided a handy reference containing information on how to prevent, recognize, treat, and reduce the impact and health effects of environmental contaminants in the community. In addition, it contains exposure history, symptoms cross-reference and environmental hazards with case studies with resources.

\section{Continuing Education and Training Resources}

Physicians can also seek training opportunities from Wisconsin Environmental Health Network and the Pediatric Environmental Health Specialty Units with consultation services (U.S. D.H.H.S., A.T.S.D.R U.S. D.H.H.S., A.T.S.D.R.) providing information and consultation contained in the information below with links in the references.

The Wisconsin Environmental Health Network was created in 2004 to provide access to Web-based resources and materials, offering regional conferences, issuing monthly emails related to environmental health issues to support physicians to influence policy to protect public health and become a better communicator (Vohmann and Meyer, 2006). In addition, the Pediatric Environmental Health Specialty Units was established by the U.S. D.H.H.S., A.T.S.D.R and includes 12 sites across the United States designed to diagnose and treat children with diseases linked to environmental exposure, reduce treats to exposure to environmental toxicants, to provide access to environmental medicine expertise, to improve health prevention (Landrigan et al., 2007). Environmental health training needs to be integrated in physician training (Sanborn et al., 2019) and it can be integrated in current training (Gehle et al., 2011). Pediatricians can reduce children's exposures and educate families but, more training in diseases of environmental origin is needed (Trasande et al., 2006; Williamson et al., 2017). The community sometimes seeks advice related to health conditions that they perceive is related to an environmental exposure. Conducting an occupational and environmental survey history is critical to evaluating environmental exposure related to health conditions. This will enable the physician to be an agent of change for community intervention one patient at a time.

The United States Environmental Protection Agency (U.S. E.P.A.) Superfund Annual Report in 1998 discusses delivery of medical services through the U.S. Public Health Service to respond to community health concerns near Hazardous waste sites. There were 4 sites targeted in the communities, involving potential exposures to hazardous substances. This report focuses on building environmental health expertise through physician training and placement, medical testing related to the hazardous site, technical assistance and environmental health training and medical follow-up (U.S. E.P.A., 1998). In addition, U.S. D.H.H.S., A.T.S.D.R. provides environmental health continuing education with case studies available for health professionals in environmental medicine (U.S. D.H.H.S., A.T.S.D.R., 2020).

In the future, we intend to update the environmental medicine training for both the ash and Kerr-McGee sites. The 
latter is a 31 -acre site where a chemical plant manufactured fertilizer, pesticide and herbicide formulations and packaging, and stored these materials in health zone 1, zip code 32206.

This training will include concepts of cultural humility and cultural competency. Mutual respect is very important with communities and individuals (Pew Health Professions Commission, 1995; Committee on the Future of Primary Care, 1994; Tresolini, Pew-Fetzer Task Force, 1994; Accreditation Council for graduate Medical Education, 1995). African Americans and other ethnic minorities report less input in their care, reduced medical decisions resulting in dissatisfaction and may be attributed to patient and physician attitudes affecting the relationship (Cooper et. al., 2003). Physicians are unprepared to deal with socio-cultural issues including religious beliefs, mistrust of medical system, new immigrants, patient's health care beliefs (Weissman et al., 2005). Patients from diverse backgrounds are more likely to experience adverse health outcomes, low quality of care or feel dissatisfied with how they were treated (Ihara, 2004). There is a training need for special needs and vulnerabilities of African Americans (Yeager and Bauer, 2014).

\section{Limitations}

The survey questions were not included because the FL DOH-Duval County could not locate the survey materials but only provided the abbreviated topic of questions summarized from the original questions. In addition, FL DOH-Duval County did not have the physical copies of the evaluations and the summary included were from a REEACH Quarterly Report in 2012. We are cognizant of the fact that conventionally a $10 \%$ confidence level is not considered statistically significant in most situations. We used 0.10 level of significance because our sample size is not large and not representative. For a two-sided test we reported a p-value of 0.083 . Our study is a preliminary one where we intend to recruit more participants and to have a more diverse and inclusive sample and to increase the number of sites in the future.

\section{CONCLUSION}

Although the ash sites are more than 90\% remediated in 2019 and expected to be completed in 2022, there is still a need for training and support of the community and of physicians. We intend to make this training accessible and updated as part of the continuing education efforts to address current and future contamination issues in Health Zone 1. We also intend to provide the Environmental Medicine pocket guide as a practical and useful resource. Furthermore, the cleanup of Kerr-McGee will begin in Spring 2021. In addition, we would like to include cultural competency in the updated environmental medicine workshop.

Author contributions: All co-authors have involved in all stages of this study while preparing the final version. They all agree with the results and conclusions.

Funding: Grant funded by U.S. D.H.H.S., A.T.S.D.R. U01/TS000108.

Acknowledgements: Thanks to the Jacksonville community residents for welcoming us in their community. Thanks to the Department of Health, Duval County for the development of the training and the delivery of the training to St. Vincent's Hospital and to the Department of Health Duval County.

Declaration of interest: The authors declare that they have no competing interests.

Ethics approval and consent to participate: Not applicable.

Availability of data and materials: All data generated or analyzed during this study are available for sharing when appropriate request is directed to corresponding author.

\section{REFERENCES}

Accreditation Council for Graduate Medical Education. Proposed guidelines and recommendations for the 19961997 academic year. (1995) Pediatric Review Committee, Washington D.C: U.S. Department of Health and Human Services.

Becker, A., Suther, S., Harris, C., Pawlowicz, G., DisneyTucker, G., Dutton, M., Close, F., Hilliard, A. and Gragg, R. (2019). Community-based participatory research at Jacksonville, Florida Ash Superfund site: Toxicology training to improve knowledge of the lay community. Florida Public Health Review, 15, 61-74.

Bureau of Labor Statistics (2009). Duval County. Available at: http://bis.gov/news.release/empsit.t02.htm

Cecile, M., Lemery, D., Vendittelli, F. and Sauvant-Rochat, M. (2016). Perceptions of environmental risks and health promotion attitudes of French perinatal health professionals. International Journal of Environmental Research and Public Health, 13(1255), 1-16. https://doi.org/10.3390/ijerph13121255

Cooper, L. A., Roter, D. L., Johnson, R. L., Ford, D. E., Steinwachs, D. M. and Powe, N. R. (2003). Patient -centered communication, ratings of care, and concordance of patient and physician race. Ann Intern Med., 139(11), 907915. https://doi.org/10.7326/0003-4819-139-11-2003120 20-00009

Gehle, K. S., Crawford, J. L. and Hatcher, M. T. (2011). Integrating environmental health into medical education. American Journal Prevention Medicine, 41(4, Suppl 3), S296301. https://doi.org/10.1016/j.amepre.2011.06.007

Graber, D. R., Musham, C., Bellack, J. P. and Holmes, D. (1995). Environmental health in medical schools' curricula: views of academic deans. Journal of Occupational Environmental Medicine, 37(7), 807-811. https://doi.org/10.1097/ 00043764-199507000-00009

Hamilton, W. J., Ryder, D. J., Cooper, H. P., Williams, Jr, D. M. and Weinberg, A. D. (2013). Environmental Health: A survey of Texas primary care physicians. Texas Medicine, 101(10), 62-70.

Ihara, E. (2004). Cultural competence in health care: Is it important for people with chronic conditions? Center on an aging society, 5. https://hpi.georgetown.edu/cultural/

Kilpatrick, N., Frumkin, H., Trowbridge, J., Escoffery, N. C., Geller, R. J., Rubin, L., Teague, G. and Nodvin, J. (2002). The environmental history in pediatric practice: a study of pediatricians' attitudes, beliefs, and practices. Environmental Health Perspectives, 110(8), 823-827. https://doi.org/10.1289/ehp.02110823 
Kumagai, A. K. and Lyson, M. L. (2009). Beyond cultural competence: Critical consciousness, social justice, and multicultural education. Academic Medicine, 84(6), 782787. https://doi.org/10.1097/ACM.0b013e3181a42398

Landrigan, P. J., Woolf, A. D., Gitterman, B., Lanphear, B., Forman, J., Karr, C., Moshier, E. L., Godbold, F. and Crain, E. (2007). Ambulatory pediatric association. Fellowship in pediatric environmental health: A 5-year assessment. Environmental Health Perspectives, 115(10). https://doi.org/10.1289/ehp.10015

Marshall, L., Weir, E., Abelsohn, A. and Sanborn, M. D. (2002). Why is taking an environmental exposure history important? Canadian Medical Association or its licensors, 166(8), 1049-1054.

Pediatric Environmental Health Specialty Units. Find and Expert. Available at https://www.pehsu.net/nationalclassroom. html (Accessed: 11 February 2021).

Pew Health Professions Commission. (1995). Critical challenges: Revitalizing the health professions for twenty-first century. Center for Health Center of Health Professions. University of California, San Francisco.

Poonai, N., Diepen, v., Bharatha, A., Manduch, M., Deklaj, T. and Tarlo, S. M. (2005). Barriers to diagnosis of occupational asthma in Ontario. Canadian Journal of Public Health, 130(2), 230-233. https://doi.org/10.1007/ BF03403697

Pope A. M. and Rall, D. P. (1995). Environmental medicine: Integrating a missing element into medical education. National Academy Press, Washington D.C. https://doi.org/10.1001/jama.1995.03530010027011

Sanborn, M. D. and Scott, E. A. (1998). Environmental health concerns in urban and rural family practice. Canadian Family Physician, 44, 1466-1472.

Sanborn, M., Grierson, L., Upshur, R., Marshall, L., Vakil, C., Griffith, L., Scott, F., Benusic, M. and Cole, D. (2019). Family medicine residents' knowledge of, attitudes toward, and clinical practices related to environmental health. Canadian Family Physician, 65, e269-e277.

Trasande, L., Schapiro, M. L., Falk, R., Haynes, K. A., Behrmann, A., et al. (2006). Pediatrician attitudes, clinical activities, and knowledge of environmental health in Wisconsin. Wisconsin Medical Journal, 105(2), 45.

Tresolini, C. and Pew-Fetzer Task Force. (1994) Health Professions education and relationship-centered care. San Francisco: Pew Health Professional Commission.

United States Census (2000). Duval county data. Available at: http://www.census.gov

United States Department of Health and Human Services. Agency of Toxic Substances and Disease Registry (U.S. D.H.H.S., A.T.S.D.R.). (updated 2020). Resources for Health Professionals Health Studies. Available at: https://www. atsdr.cdc.gov/csem/csem.html (Accessed: 6 March 2021).

United States Department of Health and Human Services. Agency of Toxic Substances and Disease Registry (U.S. D.H.H.S., A.T.S.D.R.) (2015) Introduction to toxicology. Available at: https://www.atsdr.cdc.gov/training/tox manual/modules/1/ (Accessed: 17 March 2021).
United States Department of Health and Human Services. Agency of Toxic Substances and Disease Registry (U.S. D.H.H.S., A.T.S.D.R.) (2015). Routes of exposure. Available at: https://www.atsdr.cdc.gov/training/toxmanual/module s/2/ (Accessed: 17 March 2021).

United States Department of Health and Human Services. Agency of Toxic Substances and Disease Registry (U.S. D.H.H.S., A.T.S.D.R.) (2015). Risk Assessment. Available at: https:/www.atsdr.cdc.gov/training/toxmanual/modules/3 /index.html (Accessed: 20 March 2021).

United States Department of Health and Human Services. Agency of Toxic Substances and Disease Registry (U.S. D.H.H.S., A.T.S.D.R.) (2015). Survey of Toxic Substances. Available at https://www.atsdr.cdc.gov/training/tox manual/modules/4/index.html (Accessed:17 March 2021).

United States Environmental Protection Agency (U.S. E.P.A.) (2019). Cleanup Activities Available at: https://cumulis.epa.gov/supercpad/SiteProfiles/index.cfm ?fuseaction=second.Cleanup \&id=0407002\# content (Accessed: 10 March 2021).

United States Environmental Protection Agency (U.S. E.P.A.), Cleanup activities (Updated March 17, 2021). Available at: https://cumulis.epa.gov/supercpad/SiteProfiles/index.cfm ?fuseaction=second.Cleanup \&id=0407002\#bkground (Accessed: 17 March 2021).

United States Environmental Protection Agency (U.S. E.P.A.). (1998). Superfund Reforms Annual Report FY 1998. EPA report 330 R-98 001, Washington D.C.

United States, Environmental Protection Agency (U.S. E.P.A.) (2010). Available at: http://www.epa.gov/region4/waste/ npl/nplfln/kerrmcfl.htm. Feb.2021 (Accessed: 17 March 2021).

United Zip Codes. Org. Search by Zip, address, city, and county. Updated 2021 Available at: https://www.unitedstates zipcodes.org (Accessed: 16 February 2021).

Vohmann, M. and Meyer, A. C. (2006). Wisconsin Environmental Network-A new resource for Wisconsin Physicians. Wisconsin Medical Journal, 105(2), 11.

Walters, G. I., McGrath, E. E. and Ayres, J. G. (2012). Audit of the recording of occupational asthma in primary care. Occupational Medicine, 62(7), 570-573. https://doi.org/ 10.1093/occmed/kqs114

Weissman, J. S., Betancourt, J., Campbell, E. G., Park, E. R., Kim, M., Clarridge, N. and Maina, A. W., (2005). Resident physicians' preparedness to provide cross-cultural care. Journal of the American Medical Association, 294(9), 10581067. https://doi.org/10.1001/jama.294.9.1058

Wigle, D. (2000). Child health and the environment. Patient Care Canada, 11, 54-62.

Williamson, L., Sangster, S., Bayly, M., Gibson, K., Lawson, K. and Clark, M. (2014). A needs assessment on addressing environmental health issues within reproductive health service provision: Considerations for continuing education and support. Canadian Medical Education Journal, 8(4), e65e73. https://doi.org/10.36834/cmej.36863 
Wisconsin Environmental Health Network. Available at https://www.wehnonline.org (Accessed: 11 February 2021).

Yeager, K. A. and Bauer-Wu, S. (2013). Cultural humility: Essential foundation for clinical researchers. Appl Nurs Res, 26(4), 251-256. https://doi.org/10.1016/j.apnr.2013. 06.008
Zachek, C., Miller, M., Hsu, C., Schiffman, J., Sallan, S., Metayer C. and Dahl, G. (2015). Children's cancer and environmental exposures: Professional attitudes and practices. Journal Pediatric Hematological Oncologists, 37, 491-497. https://doi.org/10.1097/MPH.0000000000000416 